$5^{\text {th }}$ International Conference on Innovation in Science and Technology

Barcelona - Spain

ISTCONF

7 - 9 December, 2018

\title{
TOTAL WATER STORAGE ON TERRITORY OF POLAND - COMPARISON AND ANALYSIS OF GRACE AND GLDAS VALUES
}

Zofia Rzepecka, Monika Biryło

University of Warmia and Mazury in Olsztyn, Poland

\begin{abstract}
Water and its resources are especially important component of the natural environment. Water resources should be monitored, because they are of great importance for nature and the economy. This presentation starts with definition of the Total Water Storage (TWS), then the GRACE mission and GLDAS system are discussed as the two main ways of obtaining information on TWS. Analyzes of TWS were carried out for the territory of Poland. There are two main rivers in Poland: Vistula and Odra, their basins cover almost whole area of the country. The data averaged over these two basins were analyzed. The results of comparisons carried out for 4 GLDAS sub-models (CLM, NOAH, MOSAIC, VIC) and data obtained from GRACE observations are presented. All data sets have been tested in terms of seasonal components and the trend values occurring in them. Trend values were additionaly tested for their statistical significance, applying the Mann-Kendall trend tests. The results are presented in graphical and descriptive form.
\end{abstract}

Keywords: equivalent water height EWH; GLDAS; GRACE; Mann-Kendall test; Terrestrial water storage TWS; 